University of Louisville

ThinkIR: The University of Louisville's Institutional Repository

\title{
Attitudes, perceptions, and usage of electronic cigarettes : an exploratory investigation.
}

\author{
Elizabeth P Hart \\ University of Louisville
}

Follow this and additional works at: https://ir.library.louisville.edu/honors

Part of the Health Communication Commons

\section{Recommended Citation}

Hart, Elizabeth P, "Attitudes, perceptions, and usage of electronic cigarettes : an exploratory investigation." (2017). College of Arts \& Sciences Senior Honors Theses. Paper 132.

http://doi.org/10.18297/honors/132

This Senior Honors Thesis is brought to you for free and open access by the College of Arts \& Sciences at ThinkIR: The University of Louisville's Institutional Repository. It has been accepted for inclusion in College of Arts \& Sciences Senior Honors Theses by an authorized administrator of ThinkIR: The University of Louisville's Institutional Repository. This title appears here courtesy of the author, who has retained all other copyrights. For more information, please contact thinkir@louisville.edu. 


\title{
ATTITUDES, PERCEPTIONS, AND USAGE OF ELECTRONIC CIGARETTES: AN EXPLORATORY INVESTIGATION
}

\author{
By
}

Elizabeth Paige Hart

Submitted in partial fulfillment of the requirements for Graduation summa cum laude and for Graduation with Honors from the Department of Communication University of Louisville

May 2017 


\section{ACKNOWLEDGMENTS}

This thesis would only be but a dream, if it were not for the inspiration and advice graciously given by my mentors, Dr. Joy Hart, Dr. Kandi Walker, and Clara Sears. I cannot thank you enough for your support, guidance, laughs, and dedication to seeing me complete my thesis. Also, I could not have finished without the encouragement of my family; thank you Mom, Dad, and Kate. Lastly, I am forever grateful to the University of Louisville community for their support in making my thesis possible. 


\section{Table of Contents}

Acknowledgments

List of Tables

iv

ABSTRACT

xii

BACKGROUND

Electronic Cigarettes

Regulation

Promotion

Perceptions and Realities

E-cig Usage

Youth Usage

College Usage

6

6

7

SPECIFIC AIMS AND HYPOTHESES

METHODS

Participants

Procedure

19

Student E-cig Survey

Statistical Analysis

RESULTS

DISCUSSION

Limitations

32

Future Directions

CONCLUSION

REFERENCES

APPENDIX A 


\section{LIST OF TABLES}

Table 1: Demographics of Participants

Table 2: Involvement and E-cig Usage 24

Table 3: Health and Safety Perceptions $\quad 26$

$\begin{array}{lr}\text { Table 4: Ingredients and Safety } & 28\end{array}$ 


\begin{abstract}
Electronic cigarettes (e-cigs) are increasing in popularity. Originally, e-cigs were marketed and sold primarily online, but now they are easily accessible in a variety of locations, such as specialty and convenience stores, retail outlets, as well as online. Despite the increasing popularity of these devices, little is known about the overall health effects of using e-cigs. Additionally, relatively few studies have explored users' and nonusers' perceptions of and attitudes about the devices and their use. The primary objective of this study was to address that gap by examining perceptions of and attitudes about ecigs from users and non-users. A questionnaire was used to obtain information about participants' attitudes, perceptions, and usage of e-cigs. Surprisingly, $6 \%$ of the sample had not heard of e-cigs and only $7.1 \%$ were current e-cigarette (e-cig) users. E-cig users were characterized as males with lower GPAs and lower self-reported overall health. Ecig users were most involved with Greek life, spent the least time studying, and spent the most time involved with RSOs and exercising. Generally, e-cigs were perceived as unsafe and an unhealthy option, and participants were unsure of the ingredients contained in ecig vapor. This information may be beneficial in developing more informative health communication material.
\end{abstract}





\section{BACKGROUND}

Electronic nicotine delivery systems, ENDS, are taking the tobacco market by storm. ENDS include vaporizers, vape pens, hookah pens, electronic cigarettes (e-cigs), and electronic pipes. E-cigs are defined as battery-powered devices that aerosolize eliquid and other additives for inhalation, but do not burn tobacco (Rigotti, 2012). Typically, e-cigs are made of cartridges that may or may not contain nicotine, along with a component to produce the aerosol, usually propylene glycol. An e-cig has a battery with an atomizer, cartomizer, or clearomizer that delivers the liquid in an aerosolized form (FDA, 2016). Specific parts vary based on the brand of e-cigs and product make-up (Cobb, Byron, Abrams, \& Shields, 2010).

E-cigs can be disposable or reusable and fall into three overarching categories: cigalike, vape pen, and mod (Smith et al., 2013). A cigalike is similar in appearance to a traditional cigarette and typically comes pre-filled. A vape pen tends to be between the size of a cigalike and a mod and is typically refillable. A module, mod for short, is the largest of the three with refillable e-liquid with cartridges. Because there is no combustion, e-cigs do not produce smoke (Smith et al., 2013). A traditional cigarette is smoked, whereas an e-cig is "vaped."

E- cig liquid contains roughly $10-40 \mathrm{mg} / \mathrm{mL}$ of flavoring chemicals (Tierney, Karpinski, Brown, Wentai, \& Pankow, 2016). The assortment of flavors used in e-cig liquid is a main marketing point for e-cigs (Tierney et al., 2016). The vast majority of flavors are not tobacco-related (e.g., menthol), but confectionary in nature (e.g., strawberry, chocolate, grape, etc.) (Tierney et al., 2016). The variety of flavor options 
may entice youth to try or experiment with e-cigs. In addition, the ability to purchase ecigs online can encourage youth to procure and try these products.

Many of the flavor additives in e-liquid contain aldehydes, which are "a "primary irritant' of the mucosal tissue of the respiratory tract" (Tierney et al., 2016, p. e10). Further, concentration of some of the flavor additives is higher than recommended intake values; therefore, the flavors themselves could pose biological concerns when inhaled (Tierney et al., 2016). Each individual flavor can have different cytotoxicities. For example, a chocolate flavor molecule known as 2,5-dimethylpyrazine can activate CFTR, posing harmful consequences to the surface liquid of human airways for individuals who use e-cigs often (Sherwood \& Boitano, 2016). Although dangers of the flavor additives themselves warrant reconsideration of e-cig use, marketing claims frequently emphasize safety. Flavors add to e-cig appeal, often encouraging experimentation; therefore, a possible prevention mechanism would be limiting or disallowing e-cig flavors (Kong, Morean, Cavallo, Camenga, \& Krishnan-Sarin, 2015).

\section{Regulation}

Due to the relative newness of e-cigs and their marketing, facets of regulation are still debated. The U.S. Food and Drug Administration (FDA) was given the authority to regulate tobacco products by the Family Smoking Prevention and Tobacco Control Act of 2009. This Act originally defined tobacco products as any product made from tobacco that is not a drug-device combination (FDA, 2016). A drug-device combination product is defined as a product composed of any combination of two of the following: a drug, a device, or a biological product (FDA, 2016). Under these definitions, e-cigs were not initially regarded as tobacco products under the 2009 Family Smoking Prevention and 
Tobacco Control Act, but as drug-device combination products because they were being marketed as cessation tools. Because e-cigs were marketed as therapeutic, they could be controlled under the FDA Center for Drug Evaluation and Research. However, the outcome of Sottera, Inc. v. U.S. FDA (2010) determined that e-cigs, unless specifically classified as therapeutic, were a tobacco product, rather than a drug-device combination product. After this finding, the FDA declared its intention to regulate e-cigs as tobacco products (Sottera Inc. v. U.S. FDA, 2010).

Even prior to loose federal regulation of e-cigs in 2010, as many as 43 states restricted minors from purchasing these products (Tierney et al., 2016). As previously mentioned, in 2009, the Tobacco Control Act was signed into effect, but did not cover ecigs; so many states began to pass bills (FDA, 2016). Oregon announced that companies must give the Attorney General advanced notice if they plan to sell e-cigs (FDA, 2016). E-cigs sales were banned to persons under the age of 19 in New York (FDA, 2016). California passed a bill to prohibit the sale of e-cigs (FDA, 2016). Amazon even suspended sales of ENDS from their website (FDA, 2016). Until these products are extensively researched and perhaps more heavily regulated, many concerns (e.g., ingredients, health consequences, youth availability) remain significant.

The FDA now regulates the making, importing, packaging, labeling, advertising, selling, and distributing of ENDS, but not accessories (FDA, 2016). Even with this regulation, however, the warnings on e-cigs are not as detailed as those found on other tobacco products. In 2009, the Tobacco Control Act replaced the Surgeon General's warning with nine textual warning statements, indicating specific adverse health consequences, on cigarette products and advertisements. These statements are: 
"WARNING: cigarettes are addictive, tobacco smoke can harm your children, cigarettes cause fatal lung disease, cigarettes cause cancer, cigarettes cause strokes and heart disease, smoking during pregnancy can harm your baby, smoking can kill you, tobacco smoke causes fatal lung disease in nonsmokers, and quitting smoking now greatly reduces serious risks to your health.” However, the newly regulated ENDS products contain less specific health warnings, with one of the following statements: "WARNING: This product contains nicotine. Nicotine is an addictive chemical." or "This product is made from tobacco." if the manufacturer has data to support that no nicotine is present (FDA, 2016). If over time detrimental health effects related to e-cig use are found, these warnings may evolve to include more specific cautions. In the interim, however, marketers encourage use and tout benefits of e-cigs (FDA, 2016).

\section{Promotion}

An increase in e-cig usage has resulted in an increase in vape shops that sell ENDS product and can mix e-liquids as well (FDA, 2016). As e-cigs have become more popular and more available, the marketing of these devices has proliferated (Wagoner et al., 2014). Between 2011-2012, advertising expenses for e-cigs increased from 6.4 million to 18.3 million dollars (King, Patel, Nguyen, \& Dube, 2015). Beyond traditional marketing venues, a growing trend of e-cig marketing on social media platforms has taken hold (Jidong, Kornfield, Szczypka, \& Emery, 2014). Twitter seems to be the most popular social media platform e-cig companies use to target their audiences (Jidong et al., 2014). For example, one study classified tweets as 'commercial' if price and links to purchase e-cigs were mentioned and 'organic' if individual views and experiences were the focus. Of all e-cig tweets, 90\% were commercial ones (Jidong et al., 2014). 
Marketing efforts whether online or face-to-face often insinuate or directly state that e-cigs emit only water vapor, but there is evidence that toxins and carcinogens are also present in e-cigs (e.g., acetaldehyde, acrolein, toluene, nitrosamines) (Drummond \& Upson, 2014). In the absence of evidence-based public health messaging, advertisements may be promoting beliefs and behaviors that lead to increased use of e-cigs (Duke et al., 2014).

Although e-cigs are often marketed as a key cession tool to quit smoking traditional cigarettes, questions remain regarding their effectiveness in cessation. Some people have reported feeling fewer urges to smoke a traditional cigarette, while using ecigs as a cessation aid, due to fewer side effects and the dose of nicotine being delivered in a similar fashion as a traditional cigarette (Palazzolo, 2013). And although some people reduce their use of traditional cigarettes or quit entirely, studies suggest that individuals tend to become dual users (i.e., using both traditional cigarettes and e-cigs), perhaps increasing their overall consumption of nicotine (Rigotti, 2012). Rigotti (2012) noted "the absence of scientific data on its [e-cig] safety or efficacy for cessation" and recommended discouraging e-cigs as a cessation method (pp. 1579).

\section{Perceptions and Realities}

Marketing can be a source of information about e-cigs that can develop perceptions. E-cigs are often perceived as completely safe and healthy, adding to their popularity. Despite no agreed upon scientific evidence that e-cigs are healthy, some people believe that these products are healthier than traditional tobacco products. Although the combustion of tobacco produces many carcinogens, there are other compounds/ingredients found in the product that can contribute to the carcinogic effect 
(Cobb et al., 2010). Perhaps not surprisingly, e-cig users are more likely to perceive ecigs as less dangerous compared to traditional cigarettes (Amrock et al., 2015). There is also a gender difference, with males perceiving e-cigs less harmful than females do (Amrock et al., 2015).

The perception that e-cigs are harmless is not supported by research. For example, in a recent study conducted to identify the effect of e-cig exposure, researchers found exposure to aerosol, either with nicotine or without nicotine, decreased cell viability and survival, while increasing programed cell death like apoptosis and necrosis (Yu et al., 2016). Cells that were exposed to e-cig aerosol also saw an increase in DNA strand breaking, which can lead to mutations and potentially cancer (Yu et al., 2016). Yu and colleagues (2016) concluded that e-cigs were not as safe as depicted in advertisements. Although carcinogens were not specifically investigated in the aforementioned study, it does yield evidence that containments exist in the aerosol produced (Yu et al., 2016). Other emerging research has suggested that e-cig cartridges, solutions, and aerosol contain potentially harmful products (e.g., nitrosamines, diethylene glycol; Westenberger, 2009).

The amount of nicotine can also vary by different brands of e-liquid purchased and disposable e-cigs. Nicotine is a highly addictive substance that actives the same pathway in the brain as drug addictions (Schraufnagel, 2015). The dangers of nicotine are well documented; for example, in adolescents and young adults, it can negatively affect brain development (Schraufnagel, 2015). One concern with e-cigs is the delivery of nicotine, with studies showing conflicting levels of nicotine in the blood after one "puff" of an e-cig (Bullen et al., 2010; Dawkins \& Corcoran, 2013; Eissenburg et al., 2010; 
Vansickel \& Eissenberg, 2013). These results suggest the possibility of varying amounts in nicotine consumption per "puff" and hence addiction due to e-cig usage is feasible (Palazzolo, 2013). Despite the perception that e-cigs are reducing harmful effects compared to traditional cigarettes, scientific evidence is inconclusive at present (Palazzolo, 2013).

Another key perception that may encourage e-cig use is overall cost, with many believing e-cigs are a cheaper alternative to traditional cigarettes (Schraufnagel, 2015). Though the initial cost for an e-cig can be higher than a traditional pack of cigarettes, over time e-cigs may be less expensive. On average, a pack of conventional cigarettes, containing 20 cigarettes, can cost between $\$ 5$ and $\$ 14$ (Smith, Brar, Srinivasan, Enja, \& Lippmann, 2016). In contrast, a refillable e-cig costs between $\$ 10$ and $\$ 15$, with a refill tank "last[ing] as long as about 150 cigarettes" according to Blu, a well-known e-cig company (Blu, 2017). Although there may be additional costs of repairing an e-cig mod, users may spend less overall than on conventional cigarettes.

Originally, e-cigs could be purchased online with little verifying information. Now with oversight from the FDA, the sale of e-cigs has been regulated to permit selling of e-cigs to persons over the age of 18 with a photo ID to confirm age, if under 27 (FDA, 2016). No free samples of ENDS can be distributed and ENDS may only be sold in vending machines at adult-only facilities (FDA, 2016)

\section{E-cig Usage}

Across all age cohorts, studies reveal that the awareness and use of e-cigs are increasing (King, et al., 2013). When looking at awareness of e-cigs, a gender difference between males and females does not seem to exist (Amrock et al., 2015), but awareness is 
higher in current smokers than in never-smokers or former smokers (King, Alam,

Promoff, Arrazola, \& Dube, 2013). However, a gender disparity has been found in regard to e-cig usage, with males being more likely than females to have used or currently use them (Amrock et al., 2015). One study found that current use of e-cigs was higher for non-Hispanic white people and individuals with a college degree, living in the south, and who currently use traditional cigarettes (King et al., 2015). This finding helps to characterize e-cig users. Schrafnagel (2015) also found that young white people with higher incomes are most likely to use e-cigs.

Palazzolo (2013) reported that current cigarette smokers were more likely to use e- cigs. Of the ever increasing e-cig users, $12 \%$ were never smokers, $30 \%$ were former or experimental smokers, $33 \%$ were current non-daily smokers, and $9 \%$ were current daily smokers compared to $53 \%, 19 \%, 14 \%$, and $4 \%$, for the never e-cig users, respectively (Palazzolo, 2013). When asked if they had ever used an e-cig, even taken just one or two puffs of e-cigs, results were significantly higher for current smokers compared to both former and never-smokers (King, et al., 2013). Trumbo and Harper (2013) found that being a current or former smoker was positively associated with trying different forms of tobacco beyond cigarettes as well as being more aware of e-cigs (Trumbo \& Harper, 2013). These findings suggest that current or former smokers have a greater likelihood of trying or using e-cigs. Harper and Trumbo (2013) further noted that the perceived limited influence on non-users has lead to a greater acceptance of e-cigs and may increase their use. The main e-cig advertising tactic seems to contain both direct and indirect health claims that are not supported by medical evidence (Amrock, Zakhar, Zhou, \& Weitzman, 2015). If current trends of advertising e-cigs continue from the studies previously 
mentioned, awareness and use of e-cigs are likely to increase among all cohorts (Duke et al., 2014).

Youth Usage._Increases in use of alternative forms of tobacco, notably e-cigs, among youth and adolescents have paralleled declines in conventional cigarette use (Larson \& Pearlman, 2016). For example, one study found that $25.3 \%$ of high school youth currently used a tobacco product; the most common of these products being e-cigs (16.0\%) (Larson \& Pearlman, 2016). Between 2011 and 2015, traditional cigarette use declined and e-cig and hookah use substantially increased. Further, e-cig experimentation and recent use doubled among U.S. middle and high school students from 2011-2012 (Corey et al., 2013). A study of Rhode Island high school youth also showed that e-cig use was higher for non-Hispanic white males, consistent with finding in other research (Larson \& Pearlman, 2016). Schraufnagel (2015) showed that increases in e-cigs use corresponded with increases in grade level: $8.7 \%$ of 8 th graders, $16.2 \%$ of 10 th graders, and $17.1 \%$ of 12 th graders. These findings could suggest an even larger rise within the college population, especially due to increased freedom and possibly greater exposure to e-cigs.

The perceived safety of e-cigs also influences adolescents' use of the products. Adolescents who perceive e-cigs as a less harmful alternative to cigarettes are more likely to use e-cigs (Amrock et al., 2015). Further, e-cig users tend to believe that these products are safer than conventional cigarettes (Amrock et al., 2015). One concern with adolescents' use is the idea that e-cigs may act as a gateway and increase the likelihood conventional smoking (Larson \& Pearlman, 2016). Although there is no evidence to 
support e-cigs users switching to traditional cigarettes, this concern is discussed in many studies (Palazzolo, 2013).

Youth are susceptible to messages that promote tobacco use and with e-cig advertisements increasing more youth are being exposed (Meyer, Toborg, Denham, \& Mande, 2008). Marlboro, Newport, and Camel, the most advertised brands, were preferred most by adolescents and young adults during 2008-2010 (Corey et al., 2013). This finding emphasizes the amount of commercialization that impacts the young person's perception of tobacco products and illustrates how commercialization encourages youth to purchase from the well-advertised companies.

Marketing of e-cigs toward youth is common. For example, findings suggest that 24 million youth are reached in e-cig advertising and that $76 \%$ of youth exposure to ecigs is via cable television (Duke et al., 2014). One way that e-cigs are marketed is through the vast amount of flavors offered. Many flavors, such as bubble gum, chocolate, mint, and strawberry, make it enticing for youth to try an e-cig. Refill bottles promote the idea that users can buy many different flavors to try. A top reason for experimentation with e-cigs is flavors (Kong, Morean, Cavallo, Camenga, \& Krishnan-Sarin, 2015). Further study findings suggest that young adults perceive e-cigs and other new tobacco products favorably specifically because they come in different flavors; therefore, eliminating flavors may reduce intentions to try these products (Palazzolo, 2013).

College Population. E-cigs are becoming more commercialized, with a surge of advertisements and promotions saturating convenient stores, gas stations, as well as retailers. Initially, e-cigs could only be purchased from specific specialty stores or through the Internet; now e-cigs can be purchased nearly everywhere. This increase in 
advertising is noticeable in college towns across the U.S. (Wagoner, Song, Egan, Sutfin, Rebousin, Spangler, \& Wolfson, 2014). This marketing has apparently been successful due to the widespread occurrence of the word e-cig among college students (Trumbo \& Harper, 2013). E-cig availability dramatically increased between 2012 and 2013, from $24.7 \%$ to $59.9 \%$, in college communities in North Carolina and Virginia (Wagoner et al., 2014). Higher availability often leads to higher usage of e-cigs.

A recent study found that both users and nonusers were misinformed about the ingredients in e-cig vapor (Case, Crook, Lazard, \& Mackert, 2016). With e-cig prevalence increasing in recent years, these products were not included in college age students' tobacco education programs as youth, which means that views may be formed primarily from marketing information and informal channels (e.g., friends). Some research has suggested that users and potential users are not informed of the ingredients in e-cig liquid and vapors and would like additional information (Wiseman et al., 2016). Cooper, Loukas, Harrell, and Perry (2017) found that dual users reported lower perceived harm from e-cigs.

The driving force behind e-cig usage among college students may be enjoyment (Saddleson et al., 2016), which likely aids in the popularity of e-cigs. Further findings suggest that college e-cig usage was not motivated by the desire to quit smoking (Saddleson et al., 2016; Sutfin, McCoy, Morrell, Hoeppner, \& Wolfson, 2013).

Across college campuses, limited research has been done about the extent of use among different groups. However, recent research has shown that college males who are conventional cigarette users seem to have greater use of e-cigs - whether current or past similar to general findings outside campuses (Sutfin et al., 2013). In addition, affiliation 
with a Greek organization has been found to significantly predict trying e-cigs (Sutfin et al., 2013). Also, as noted above, among traditional age college students using e-cigs does not appear to be motivated by any intention to quit smoking (Palazzolo, 2013).

\section{SPECIFIC AIMS AND HYPOTHESES}

As stated above, the awareness and use of e-cigs are increasing (King et al., 2013). Factors such as perceived safety, wide availability, extensive advertising, and loose regulation culminate in the growing popularity of e-cigs (Smith et al., 2016). E-cig research is advancing, and a limited number of studies have explored perception and use on college campuses, with none looking at knowledge of e-cigs. College students are an important demographic to explore because previous studies have indicated that educated young people are the main users (King et al., 2015; Schrafnagel, 2015). This study had three specific aims to investigate the following:

Specific Aim 1: To characterize e-cig use on the University of Louisville campus and compare demographics of participants that never tried, have tried, and currently use e-cigs.

Specific Aim 2: To explore the relationship between involvement in extracurricular activities, work, and school with use of e-cigs to further identify the characteristics of e-cig users.

Specific Aim 3: To compare safety and health perceptions among participants that never tried, have tried, and currently use e-cigs.

The specific aims have the following hypotheses: 
Hypothesis 1: I predict that use of e-cigs among the male population will be higher than among the female population.

Hypothesis 2: I hypothesize the more involved a person is with extracurricular activities, work, and school, the less likely they are to use an e-cigs.

Hypothesis 3: I predict that college students will have favorable perceptions of ecigarettes, viewing them as safer and healthier than traditional tobacco products. I also predict that a majority of students will view them as safe and healthy.

\section{METHODS}

\section{Participants}

Approval for this study was obtained from the Institutional Review Board at the University of Louisville. Participants $(N=652)$ were currently enrolled at the University of Louisville, a large metropolitan mid-western public university, in the spring semester of 2017. To participate in the study, individuals had to meet the following study inclusion criteria: be an undergraduate or graduate student at the University of Louisville and be at least 18 years old. Participants were instructed that participation in this survey was completely voluntary and were given time to ask questions if needed. Participants agreed to participate in the survey by completing and submitting the questionnaire electronically in RedCap.

\section{Procedure}

The survey was administered in required and elective communication courses. Participants were also recruited by passing out flyers containing the URL link to the 
questionnaire in public places. In addition, the snowball procedure was utilized, and participants were invited to share the link with other students.

\section{Student E-Cig Survey}

Participants completed a survey about e-cigs and demographics; the survey is contained in Appendix A. It took participants approximately 15 minutes or less to complete the 96 question survey. The questions assessed participants' knowledge, usage, attitudes, and perception of e-cigs. The demographic questionnaire included questions about the participant's gender, income, involvement in school, major, length of time in college, grade point average, and working status. The questionnaire also assessed participants' perceptions of the safety of traditional and e-cigs, temptation to use e-cigs, and knowledge of ingredients in traditional cigarettes and e-cigs. In addition, current ecig users were asked about use behaviors and sources of information about e-cigs.

\section{Statistical Analysis}

Statistical analysis was performed with Excel. Of the 652 completed surveys, $93.8 \%(612)$ of the participants had heard of e-cigs and $90.2 \%$ (588) completed questions about e-cig use. Three different e-cig use groups were created: never tried, tried, and users. "Never tried" was defined as participants that responded "No" to the question "Have you ever tried an electronic cigarette, even if it was just one puff?" and reported no e-cig use in the past 30 days. "Users" was defined as people who used an e-cig in the past 30 days. "Tried" was defined as participants that answered, "Yes" to the question "Have you ever tried an electronic cigarette, even if it was just one puff?" and reported no e-cig use in the past 30 days. In addition, people who chose "Yes" to the question "Have you ever tried an electronic cigarette, even if it was just one puff?" but did not 
answer the question about e-cig use in the past 30 days were classified as "tried" $(\mathrm{n}=177)$. If people answered no to ever tried a puff then they were placed in a never tried category. Participants who did not answer the question "Have you ever tried an electronic cigarette, even if it was just one puff?" were considered "never tried" (n=369).

Descriptive analysis (mean, standard deviation, median, and range) was used to compare never tried, tried, and users. Chi-squared test was used to compare categorical variables and ANOVA was used to compare continuous variables. Two sided $\mathrm{p}$-values are reported; differences were significant at $\mathrm{p}<0.05$. To investigate the first aim, demographic information was compared among the three categories of never tried, tried, and users. The second aim was accomplished by comparing participants' work schedule (full time, part time, or not employed) and involvement in different organizations (i.e., Greek life, Registered Student Organization (RSO), U of L Athletics, Intramurals, Religious groups) with their use of e-cigs. In addition, the amount of time spent with organizations, exercising, and studying was analyzed hours per week and compared among the e-cig use groups. The third aim was addressed by analyzing a variety of questions. The questions are as follows, "Electronic cigarettes are tobacco products; Vape from electronic cigarettes is safe to others; Electronic cigarettes are safe; I consider electronic cigarettes a healthy option; Flavorings are generally recognized as safe by the U.S. Food \& Drug Administration; Electronic cigarettes are safer than traditional cigarettes because they do not produce any particulate matter; and There is no conclusive evidence showing e-cigarettes are not safe, therefore electronic cigarettes are safer than traditional cigarettes." Response options were: strongly agree, agree, neutral, disagree, or strongly disagree. Responses were categorized as yes (strongly agree and agree), maybe 
(neutral), and no (disagree and strongly disagree) for analysis. In addition, further questions assessed the participants' perception of nine ingredients (formaldehyde, particulate matter, tar, nicotine, propylene glycol, water vapor, glycerin, acrolein, and flavorings) and whether they are contained in traditional cigarettes or e-cig vapor as well as if they are harmful.

\section{RESULTS}

The total sample size that had heard of e-cigs was $N=588$ with never tried $(62.8 \%$ $(n=369))$, tried $(30.1 \%(n=177))$, and users $(7.1 \%(n=42))$. Table 1 shows the demographic characteristics of the study participants. 
TABLE 1: Demographics of Participants

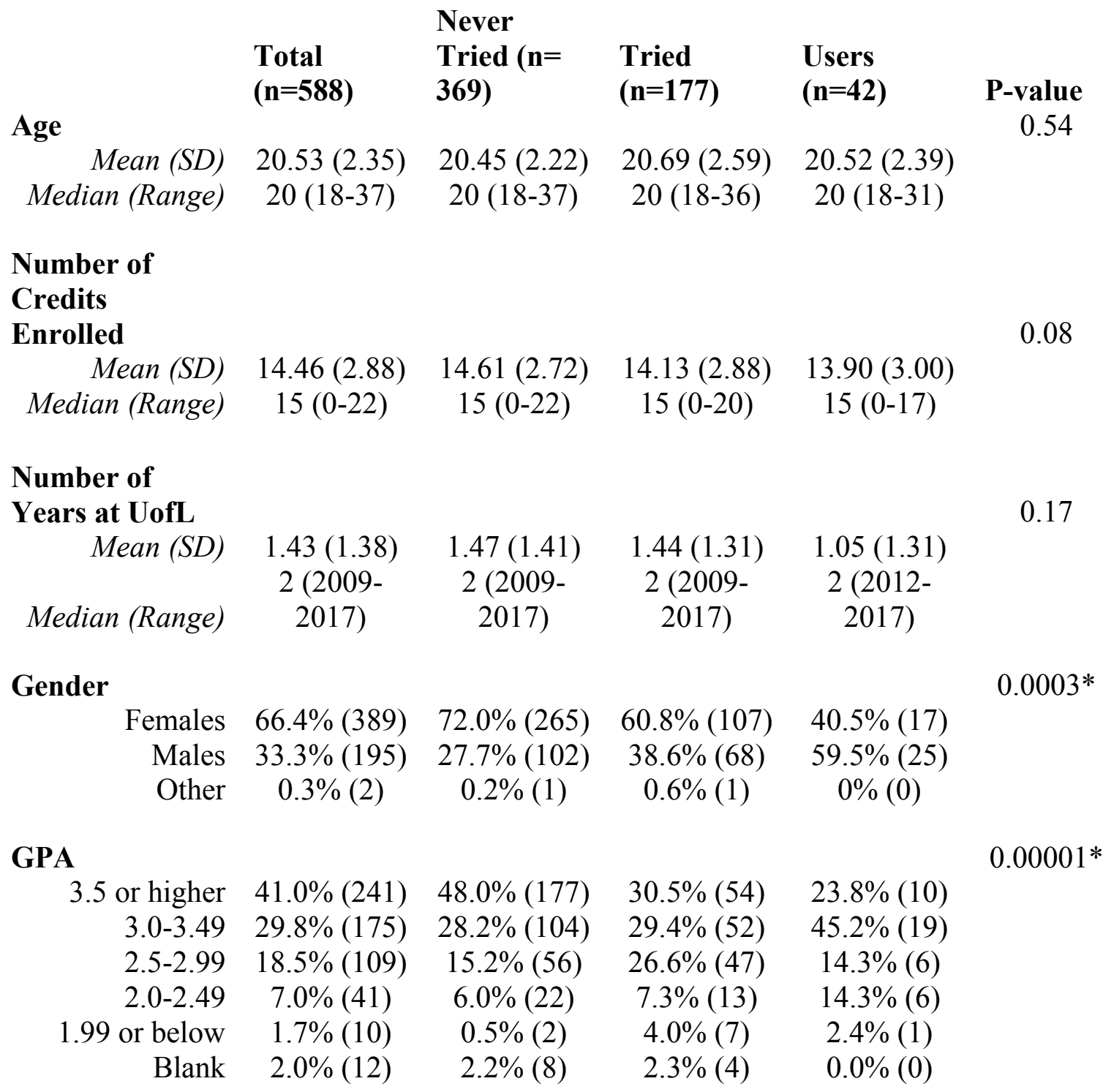

\section{Rate Overall}

Health

$\begin{array}{rcccc}\text { Excellent } & 15.1 \%(89) & 17.9 \%(66) & 11.3 \%(20) & 7.1 \%(3) \\ \text { Very Good } & 47.9 \%(282) & 51.8 \%(191) & 42.4 \%(75) & 38.1 \%(16) \\ \text { Good } & 31.6 \%(186) & 26.9 \%(99) & 37.9 \%(67) & 47.6 \%(20) \\ \text { Fair } & 4.6 \%(27) & 2.7 \%(10) & 8.0 \%(14) & 7.1 \%(3) \\ \text { Poor } & 0.7 \%(4) & 0.8 \%(3) & 0.6 \%(1) & 0.0 \%(0)\end{array}$

* Significance with a two-tailed test and $\mathrm{p}<0.05$

No significant difference was noted between the average ages, median of credits enrolled, or time spent at the university among the e-cig user categories. There was no 
significant difference in the average age of participants that had never tried, tried, or current users $p=0.54$ (average age-never users $=20.45+/-2.22$ years, tried $=20.69+/-$ 2.59 years, users $=20.52+/-2.39$ years). Participants that currently use e-cigs were taking slightly fewer credit hours (mean=13.9, standard deviation=3.0) compared to those that had tried $($ mean=14.13, standard deviation=2.88) or never tried (mean=14.61, standard deviation=2.72). Participants that never tried or tried e-cigs had been enrolled at $\mathrm{U}$ of $\mathrm{L}$ for slightly longer than current users (average years enrolled at $\mathrm{U}$ of $\mathrm{L}$ (SD), never tried $=1.47(1.41)$ years, tried=1.44(1.31) years and users= $1.05(1.31)$ years $)$.

Significance was found for gender and grade point average ( $\mathrm{p}$-value $=0.0003$, $0.00001)$. The gender for "never tried" $(72.0 \%$ females $(\mathrm{n}=265), 27.7 \%$ males $(\mathrm{n}=102)$ and $0.2 \%(\mathrm{n}=1)$ other $)$ and "tried" $(60.8 \%(\mathrm{n}=107)$ females, $38.6 \%(\mathrm{n}=68)$ males and $0.6 \%(\mathrm{n}=1)$ other) were a majority of females, while the current users were primarily males $(40.5 \%(\mathrm{n}=17)$ females and $59.5 \%(\mathrm{n}=25)$ males). The grade point average for "users" was the lowest (23.8\% having a 3.5 or above), then "tried" ( $30.5 \%$ with a 3.5 GPA or above), and the highest GPA for "never tried" (48\% above a 3.5 GPA). Overall health had significant differences ( $\mathrm{p}$-value $=0.002$ ) between e-cig groups that reported excellent or very good health $(69.6 \%(n=257)$ never tried, $53.7 \%(n=95)$ tried, and $45.2 \%$ $(\mathrm{n}=19))($ Table 1).

There was no significant difference for work status or time spent with organizations, exercising, or studying between the 3 e-cig groups ( $\mathrm{p}$-value $=0.30,0.24$, $0.85,0.09)$, as shown in Table 2. 
TABLE 2: Involvement and E-cig Usage

\begin{tabular}{|c|c|c|c|c|c|}
\hline & $\begin{array}{c}\text { Total } \\
(n=588)\end{array}$ & $\begin{array}{c}\text { Never } \\
\text { Tried (n= } \\
\text { 369) }\end{array}$ & $\begin{array}{c}\text { Tried } \\
(n=177)\end{array}$ & Users $(n=42)$ & P-value \\
\hline Work Status & & & & & 0.30 \\
\hline Full Time & $5.3 \%(31)$ & $5.4 \%(20)$ & $4.5 \%(8)$ & $7.1 \%(3)$ & \\
\hline Part Time & $59.7 \%(351)$ & $56.1 \%(207)$ & $67.2 \%(119)$ & $59.5 \%(25)$ & \\
\hline Sporadic & $20.4 \%(120)$ & $21.7 \%(80)$ & $17.5 \%(31)$ & $21.4 \%(9)$ & \\
\hline Not Employed & $14.6 \%(86)$ & $16.8 \%(62)$ & $10.7 \%(19)$ & $12.0 \%(5)$ & \\
\hline \multicolumn{6}{|l|}{ University } \\
\hline Organizations & & & & & $0.003^{*}$ \\
\hline Greek life & $42.7 \%(251)$ & $42.0 \%(155)$ & $42.9 \%(76)$ & $47.6 \%(20)$ & \\
\hline RSO & $47.4 \%(279)$ & $58.0 \%(214)$ & $44.6 \%(79)$ & $38.1 \%(16)$ & \\
\hline $\begin{array}{l}\text { UofL Athletics } \\
\text { Intramural }\end{array}$ & $9.4 \%(55)$ & $11.7 \%(43)$ & $5.1 \%(9)$ & $7.1 \%(3)$ & \\
\hline Athletics & $26.2 \%(154)$ & $25.0 \%(92)$ & $24.9 \%(44)$ & $42.9 \%(18)$ & \\
\hline Religious & $15.1 \%(89)$ & $19.8 \%(73)$ & $6.8 \%(12)$ & $9.5 \%(4)$ & \\
\hline \multicolumn{6}{|l|}{ Hours with } \\
\hline Per Week & & & & & 0.24 \\
\hline Mean $(S D)$ & $8.61(7.14)$ & $8.51(8.03)$ & $8.30(10.92)$ & $10.91(10.82)$ & \\
\hline Median (Range) & $5.76(0-40)$ & $6(0-45)$ & $5(0-40)$ & $7(0-40)$ & \\
\hline \multicolumn{6}{|l|}{ Hours } \\
\hline Week & & & & & 0.85 \\
\hline Mean (SD) & $5.79(4.93)$ & $5.72(5.06)$ & $5.86(4.86)$ & $6.14(4.14)$ & \\
\hline Median (Range) & $5(0-25)$ & $5(0-20)$ & $5(0-25)$ & $5(0-20)$ & \\
\hline \multicolumn{6}{|l|}{ Hours } \\
\hline Week & & & & & 0.09 \\
\hline Mean (SD) & $12.97(9.05)$ & $13.58(9.45)$ & $12.07(8.48)$ & $11.28(7.14)$ & \\
\hline Median (Range) & $10(0-40)$ & $10(0-40)$ & $10(0-40)$ & $10(0-30)$ & \\
\hline
\end{tabular}

*Significance with a two-tailed test and $\mathrm{p}<0.05$

Part time work was more prevalent among all three groups (never tried $=56.1 \%(n=207)$, tried $=67.2 \%(n=119)$, users $=59.5 \%(n=25))$. Full time was the lowest reported among all three e-cig groups (never tried $=5.4 \%(n=20)$, tried $=4.5 \%(n=8)$, users $=7.1 \%(n=3))$. 
Interestingly, "users" are most involved with Greek life $(47.6 \%(n=20))$, while "tried" and "never tried" are most involved with an RSO $(44.6 \%(n=79)$ tried and 58.0\% $(n=214)$ never tried). As Table 2 shows, there was significance between the differences of never tried, tried, and users in university organization membership with a p-value of 0.003 , which suggests that users spend their time outside of class differently from students who have tried or never tried e-cigs.

Questions were asked to gain insight into participants' attitudes and perceptions of e-cigs (questions 58,63, 64, 65, 75, and 88) with a significant difference in answers between the three groups, as seen in Table 3. 
TABLE 3: Health and Safety Perceptions

Never
Total

Electronic cigarettes are tobacco products.

$(\mathbf{n}=\mathbf{5 8 8})$

$$
(n=369)
$$

Tried $(\mathrm{n}=177)$

Users $(n=42)$

P-value

$0.002 *$

$\begin{array}{rcc}\text { Yes } & 58.0 \%(341) & 62.1 \%(229) \\ \text { Maybe } & 17.0 \%(100) & 15.2 \%(56) \\ \text { No } & 24.0 \%(141) & 21.1 \%(78) \\ \text { Blank } & 1.0 \%(6) & 1.6 \%(6)\end{array}$

Vape from electronic cigarettes is safe to

$$
\text { Blank }
$$
others.

$\begin{array}{rcc}\text { Yes } & 11.7 \%(69) & 8.9 \%(33) \\ \text { Maybe } & 30.6 \%(180) & 26.3 \%(97) \\ \text { No } & 56.8 \%(334) & 63.4 \%(234) \\ \text { Blank } & 0.9 \%(5) & 1.4 \%(5)\end{array}$

$55.9 \%(99)$

$31.0 \%(13)$

$18.1 \%(32)$

$28.6 \%(12)$

$26.0 \%(46)$

$40.4 \%$ (17)

$0 \%(0)$

$0 \%(0)$

$12.5 \%(22)$

$39.5 \%(70)$

$33.3 \%(14)$

$48.0 \%(85)$

$31.0 \%(13)$

$0 \%(0)$

$35.7 \%(15)$

$0 \%(0)$

Electronic cigarettes are safe.

I consider electronic cigarettes a healthy option.

$$
\begin{aligned}
& \text { Yes } \\
& \text { Maybe } \\
& \text { No } \\
& \text { Blank } \\
& \text { lthy }
\end{aligned}
$$$$
\text { Yes }
$$$$
\text { Maybe }
$$$$
\text { No }
$$

Blank

Flavorings are generally recognized as safe by the U.S. Food \& Drug Administration.

Electronic cigarettes are safer than

$$
\begin{array}{r}
\text { Yes } \\
\text { Maybe } \\
\text { No } \\
\text { Blank } \\
\hline
\end{array}
$$
any particulate matter.

There is no conclusive evidence showing

$\begin{array}{rcc}\text { Yes } & 21.3 \%(125) & 19.2 \%(71) \\ \text { Maybe } & 36.1 \%(212) & 36.0 \%(133) \\ \text { No } & 40.3 \%(237) & 41.2 \%(152) \\ \text { Blank } & 2.4 \%(14) & 3.5 \%(13)\end{array}$

e-cigarettes are not safe, therefore electronic cigarettes are safer than traditional cigarettes.

$$
\begin{array}{rcc}
\text { Yes } & 13.1 \%(77) & 10.8 \%(40) \\
\text { Maybe } & 36.5 \%(215) & 35.5 \%(131) \\
\text { No } & 48.0 \%(282) & 50.1 \%(185) \\
\text { Blank } & 2.4 \%(14) & 3.5 \%(13)
\end{array}
$$

* Significance with a two-tailed test and $\mathrm{p}<0.05$ 
Among the three e-cig use groups, there was a significant difference in the number of people who considered e-cigs to be tobacco products $(p=0.002$; never tried $=$ $55.9 \%(n=99)$, tried $=31.0 \%(n=13)$, and users $=31.0 \%(n=13))$. A significant difference was seen between the three e-cig use groups in terms of whether e-cig vape is unsafe to others $(p=0.00001$; never tried $=63.4 \%(n=234)$, tried $=48.0 \%(n=85)$, and users $=$ $35.7 \%(n=15))$. Among the three e-cig use groups, there was a significant difference in the number of people who considered e-cigs as unsafe $(\mathrm{p}=0.002$; never tried $=71.2 \%$ $(n=263)$, tried $=66.6 \%(n=118)$, and users $=42.9 \%(n=18)$.

A significant difference was seen between the three e-cig use groups in terms of whether e-cigs are an unhealthy option $(\mathrm{p}=0.002$; never tried $=73.4 \%(\mathrm{n}=271)$, tried $=$ $71.2 \%(n=126)$, and users $=42.9 \%(n=18))$. "Flavorings are generally recognized as safe by the U.S. Food \& Drug Administration" was found to have a significant difference between the three e-cig groups $(p=0.026$; never tried $=31.7 \%(n=117)$, tried $=29.9 \%$ $(n=53)$, and users $=50.0 \%(n=21))$. Among the three e-cigarette use groups, there was a significant difference in the number of people who disagree with the statement, "There is no conclusive evidence showing e-cigarettes are not safe, therefore electronic cigarettes are safer than traditional cigarettes" $(\mathrm{p}=0.002$; never tried $=50.1 \%(\mathrm{n}=185)$, tried $=48.0 \%$ $(n=85)$, and users $=28.6 \%(n=12))$. Overall, perception of e-cigs is negative with "users" following that trend as well.

Table 4 shows participants' perception of whether nine ingredients are found in traditional cigarettes and/or in e-cig vapor and are harmful.

TABLE 4: Ingredients and Safety 
Formaldehyde

In traditional cigarettes

$$
\begin{array}{rr}
\text { Yes } & 69.05 \%(406) \\
\text { No } & 30.95 \%(182) \\
\text { In e-cig vapor } & \\
\text { Yes } & 37.07 \%(218) \\
\text { No } & 62.93 \%(370) \\
\text { Is harmful } & \\
\text { Yes } & 85.88 \%(505) \\
\text { No } & 14.12 \%(83)
\end{array}
$$

\section{Particulate Matter}

In traditional cigarettes

$$
\begin{array}{r}
\text { In e-cig vapor } \\
\text { Yes } \\
\text { No } \\
\text { Is harmful }
\end{array}
$$$$
\text { Yes }
$$$$
\text { No }
$$$$
\text { Yes }
$$$$
\text { No }
$$$$
\text { Yes }
$$$$
\text { No }
$$

Tar

In traditional cigarettes

$$
\text { Yes }
$$$$
\text { No }
$$

In e-cig vapor

$$
\text { Yes }
$$$$
\text { No }
$$

Nicotine

Propylene glycol

In traditional cigarettes

Yes

No

In e-cig vapor

Yes

No

Is harmfi

Yes

No

$48.3 \%$ (284)

$86.39 \%(508)$

$88.95 \%(523)$

$19.39 \%$ (114)
Total $(n=588)$
Never Tried $(n=369)$
Tried $(n=177)$

Users $(n=42)$

Users (n=42)

(1)
P-value

0.88

$69.38 \%(256)$
$30.62 \%(113)$
$39.84 \%(147)$
$60.16 \%(222)$
$85.37 \%(315)$
$14.63 \%(54)$

$67.80 \%(120)$

$28.57 \%(12)$

0.20

$32.20 \%(57) \quad 33.33 \%(14)$

$67.80 \%(120) \quad 66.67 \%(28)$

0.67

$85.88 \%$ (152) $\quad 90.48 \%(38)$

$14.12 \%(25) \quad 9.54 \%(4)$

.

$73.64 \%(433) \quad 73.17 \%(270)$

$76.84 \%(136)$

$64.29 \%(27)$

$26.83 \%(99)$

$23.16 \%(41)$

$35.71 \%(15)$

0.99

$48.51 \%(179)$

$48.02 \%(85)$

$47.62 \%(20)$

$51.49 \%(190)$

$51.98 \%(92)$

$52.38 \%(22)$

0.44

$73.45 \%(130) \quad 78.57 \%(33)$

$26.55 \%(47) \quad 21.43 \%(9)$

$70.19 \%(259)$

0.44

$85.09 \%(314)$

$86.44 \%(153)$

$78.57 \%(33)$

$13.45 \%(24)$

$21.43 \%(9)$

0.97

$15.45 \%(57)$

$15.25 \%(27)$

$16.67 \%(7)$

$84.75 \%(150)$

$83.33 \%(35)$

0.99

$86.44 \%$ (153) $\quad 85.71 \%(36)$

$86.45 \%$ (319)

$13.45 \%(24)$

$14.29 \%(6)$

$13.55(50)$

$$
13.45
$$

0.15

$90.79 \%(335)$

$86.44 \%$ (153)

$83.33 \%(35)$

$9.21 \%(34)$

$13.45 \%(24)$

$16.67 \%(7)$

$65.58 \%(242)$

$72.88 \%(129)$

$71.43 \%(30)$

$27.12 \%(48)$

$28.57 \%$ (12)

0.55

$77.97 \%(138) \quad 83.33 \%(35)$

$22.03 \%(39) \quad 16.67 \%(7)$

0.21

$81.57 \%(301)$

$18.43 \%(68)$

In traditional cigarettes

$$
\text { Yes } \quad 53.28 \%(308)
$$

$54.74 \%(202)$

$50.28 \%(89)$

$40.48 \%$ (17)

No $\quad 47.52 \%(280)$

$45.26 \%$ (167)

$49.72 \%(88) \quad 59.52 \%(25)$ 
Yes $\quad 49.83 \%(293) \quad 48.78 \%(180) \quad 49.72 \%(88) \quad 59.52 \%(25)$

No $\quad 50.17 \%(295) \quad 51.22 \%(189) \quad 50.28 \%(89) \quad 40.48 \%(17)$

Is harmful

0.68

Yes $\quad 64.80 \%(381) \quad 65.85 \%(243)$

$63.84 \%(113) \quad 59.52 \%(25)$

No $\quad 35.20 \%(207) \quad 34.15 \%(126)$

$36.16 \%(64)$

$40.48 \%(17)$

\section{Water Vapor}

In traditional cigarettes

$$
\text { Yes }
$$

$14.29 \%(84)$

No

$85.71 \%(504)$

$17.07 \%(63)$

$82.93 \%(306)$

In e-cig vapor

Yes $\quad 90.99 \%(535)$

$91.87 \%(339)$

$8.13 \%(30)$

Is harmful

$9.01 \%(53)$

Yes $\quad 17.69 \%(104)$

No $82.31 \%(484)$

$15.99 \%(59)$

$84.01 \%(310)$

Glycerin

In traditional cigarettes

$\begin{array}{rll}\text { Yes } & 47.45 \%(279) & 49.32 \%(182) \\ \text { No } & 52.55 \%(309) & 50.68 \%(187) \\ \text { In e-cig vapor } & & \\ \text { Yes } & 59.86 \%(352) & 59.35 \%(219) \\ \text { No } & 40.14 \%(236) & 40.65 \%(150) \\ \text { Is harmful } & & \\ \text { Yes } & 53.57 \%(315) & 50.14 \%(185) \\ \text { No } & 46.43 \%(273) & 49.86 \%(184)\end{array}$

$47.46 \%(84)$

$52.54 \%(93)$

$30.95 \%(13)$

$56.50 \%(100) \quad 78.57 \%(33)$

$43.50 \%$ (77)

$21.43 \%(9)$

$62.71 \%(111)$

$45.24 \%(19)$

$37.29 \%(66)$

$54.76 \%(23)$

Acrolein

In traditional cigarettes

$52.57 \%$ (194)

$47.43 \%(175)$

In e-cig vapor

Yes $\quad 53.74 \%(316)$

$46.26 \%$ (272)

(17)

$49.32 \%(182)$

Yes $\quad 47.11 \%(277)$

$50.68 \%(187)$

Is harmful

$52.89 \%(311)$

Yes $\quad 64.97 \%(382)$

$62.60 \%(231)$

No $\quad 35.03 \%(206)$

$37.40 \%$ (138)

Flavorings

In traditional cigarettes

$40.92 \%$ (151)

$59.08 \%(218)$

In e-cig vapor

Yes $\quad 41.33 \%(243)$

$58.67 \%(345)$

$89.70 \%(331)$

$10.30 \%(38)$

No $\quad 10.71 \%(63)$

Is harmful

Yes $\quad 32.48 \%(191)$

No $\quad 67.52 \%$ (397)

* Significance with a two-tailed test and $\mathrm{p}<0.05$

$30.35 \%(112)$

$69.65 \%(257)$
$55.93 \%(99) \quad 52.76 \%(23)$

$44.07 \%(78) \quad 45.24 \%(19)$

0.16

$41.24 \%(73) \quad 52.38 \%(22)$

$58.76 \%(104) \quad 47.62 \%(20)$

0.17

$70.62 \%(125) \quad 61.90 \%(26)$

$29.38 \%(52) \quad 38.10 \%(16)$

0.76

0.14

$45.20 \%(80) \quad 28.57 \%(12)$

$54.80 \%(97) \quad 71.43 \%(30)$

0.56

$87.57 \%(155) \quad 92.86 \%(39)$

$12.43 \%(22) \quad 7.14 \%(3)$

0.33 
Only three of the 27 results came back with a $p$ value less than 0.05 . Participants reported water vapor was not in traditional cigarettes $(p$-value $=0.03$; never tried $=82.93 \%$ $(n=306)$, tried $=90.96 \%(n=161)$, users $=88.10 \%(n=37))($ Table 4$)$. Participants reported that glycerin was in e-cig vapor ( $\mathrm{p}$-value $=0.03$; never tried $=59.35 \%(\mathrm{n}=219)$, tried $=56.50 \%(n=100)$, users $=78.57 \%(n=33))($ Table 4$)$. Participants reported that glycerin was not harmful $(\mathrm{p}$-value $=0.012$; never tried $=50.14 \%(\mathrm{n}=185)$, tried $=62.71 \%(\mathrm{n}=111)$, users $=45.24 \%(n=19))($ Table 4$)$.

\section{DISCUSSION}

In examining Aim 1, significant differences emerged between e-cig groups for gender, GPA, and overall health. The category "users" has a higher percent of males $(59.5 \%, n=25)$, lower overall GPAs $(23.8 \%(n=10)$ with a 3.5 or higher $)$, and fewer

reports of excellent health $(7.1 \%(n=3))$. No significance $(p$-value $=0.536,0.08,0.172)$ was found between age, course load, or number of years at the university (Table 1). These results would seem to characterize users of e-cigs as being relatively skewed toward males who have lower GPAs and somewhat more negative perceptions of their health. This characterization of users is not influenced by age or year at a university. In addition, this study supports the findings of Amrock et al. (2015) that e-cig users tend to be males and e-cig usage has a gender disparity. Characterizing users is vital in understanding who the main users of e-cigs are and can be used in future development of health promotions.

The second aim of characterizing by involvement produced interesting results. 
Current e-cig users were most involved with Greek life (47.6\% (20)), which aligns with Sutfin et al.'s (2013) findings that Greek life predicts e-cig usage. Involvement in intramural sports was a close second $(42.9 \%(\mathrm{n}=18))$, which is interesting because lungs must be healthy to facilitate sport activities and inhaling substances can be harmful. It was suggested that e-cig users, while involved with exercising and work, are not involved with academic enriching activates (e.g. studying, involved with professional organizations) while in college. Compared to other groups, current users also spent the least time studying, which could be reflected in their lower GPAs. In addition, current users had the highest average hours spent with their organizations and exercising. This finding is strange because "users" are not as involved with RSOs, but reported the most hours per week involved with their organization/s. This finding helps to characterize ecig users by examining how their time is spent outside of class.

When analyzing the perceptions of health and safety for Aim 3, participants in "tried" or "users" categories tend to respond agree/disagree rather than strongly agree/disagree. This trend in answers could illustrate a cognitive dissonance, meaning that they understand e-cigs are harmful, but continue to use. This study found that $58.0 \%$ ( $\mathrm{n}=341)$ of participants considered e-cigs to be tobacco products, whereas current users $(40.4 \%, \mathrm{n}=17)$ considered e-cigs not to be tobacco products. This ambiguity could lead to conflicts when in "no smoking" environments that do not specify if e-cigs are included. Half of e-cig users (50.0\%) agreed that flavorings are generally recognized as safe by the FDA, whereas never tried (48.8\%) and tried (44.1\%) had more maybe responses. Generally recognized as safe is a term the FDA uses for ingestion, not inhalation, of chemicals (FDA, 2016). More research is needed to fully understand the health effects of 
e-cig ingredients.

A little under half (42.9\%) of current users consider e-cigs unsafe and unhealthy, yet they still vape. When asked to consider, "There is no conclusive evidence showing that e-cigs are not safe, therefore e-cigs are safer than traditional cigarettes," half of nonusers (50.1\%) reported no, while $45 \%$ of "users" reported maybe. Collectively, these results would seem to suggest that users tend to view more components of e-cigs as relatively safe whereas never tried and tried are not as convinced. This study showed that perception of e-cigs is still variable across individuals and creating a more uniform perception will be important for regulation and cessation.

Both users and nonusers believed that e-cigs produce water vapor, which was also found by Case et al. (2016). There is a great need for education on ingredients and chemicals found in substances that are inhaled. As Table 4 reveals, there were participants that did not know that formaldehyde (30.95\%), $\operatorname{tar}(26.36 \%)$, and nicotine $(11.05 \%)$ are contained in traditional cigarettes, even though many tobacco education classes and anti-tobacco ads contain this information. A significant difference between ecig groups and their perception of glycerin in e-cig vapor was observed ( $p$-value $=0.0303$, never tried $=59.35 \%(n=219)$, tried $=56.50 \%(n=100)$, and users $=78.57 \%(n=33) ;($ Table 4)).

\section{Limitations}

One limitation of this study was that only university students from one campus were sampled. Many college age individuals are not currently enrolled at a higher education institution or are enrolled at universities other than the one studied. Their views and experiences may differ from the ones captured in this study. In short, the 
generalizability of the findings is limited. In addition, a limited number of e-cig users completed the study, limiting understanding of the perceptions, attitudes, and use patterns of e-cig users at the University of Louisville as well as the overall generalizability of the findings.

\section{Future Directions}

Given e-cigs' popularity, additional research is needed to better understand views and use of these products, as well as their overall safety. Research on advertisement techniques may yield insights into how to construct prevention messages. In this study, participants were unsure about e-cig safety and the ingredients contained in an e-cig. In the future, especially as more biomedical findings emerge, arguing against unsupported health claims put forth by marketers may prove successful in reducing e-cig consumption (Amrock et al., 2015). Another possible avenue for future study is expanding the survey to more college campuses, especially those with diverse populations. The implications of social media marketing for e-cig use and health also need further investigation.

\section{CONCLUSION}

Despite the growing popularity of e-cigs, there are still people who have not heard of them. In this study, $6 \%$ of the sample had not heard of e-cigs prior to the survey. Vaping does not appear to be widespread on this university campus, with only $7.1 \%$ of participants currently using. Use, including tried and users, of an e-cig was higher in this study $(33.6 \%)$ than in Sutfin (2013). It is important to note that a significant difference between genders was found, with males being more likely to use than females, which aligns with Amrock et al.’s (2015) findings. Users being affiliated with Greek 
organizations was also found in this study $(47.6 \%(20))$ and align with Sutfin et al.'s (2013) result that Greek life predicted e-cig usage. Among the e-cig groups, current users had lower GPAs than nonusers, which had not been previously reported and warrants further investigation.

Overall participants believed that e-cigs were tobacco products $(\mathrm{n}=58.9 \%$, $\mathrm{n}=341)$. In general, participants viewed vape from e-cigs as unsafe to others $(\mathrm{n}=334$, $56.8 \%)$, e-cigs as unsafe in general ( $\mathrm{n}=339,67.9 \%)$, and e-cigs as an unhealthy option $(\mathrm{n}=415,70.6 \%)$. Table 4 reveals that people still do not know what is in traditional cigarettes and do not know what in is e-cig vapor.

The findings also reveal that participants are willing to vape (try e-cigs or use consistently) without knowing what an e-cig contains (see Table 4). Such results suggest the need for more explicit information to educate both users and potential users about ecigs. One participant stressed interest in learning more by stating, "I'd like to know more information about E-Cigs in order to give appropriate answers as to whether or not I think they are a safer option to traditional cigs... I don't know much information about E-cigs, therefore I couldn't give helpful answers." Future health communication campaigns might consider raising awareness in these areas.

Despite growth in e-cig research and interest in college students, the e-cig knowledge of college students, their perception of safety, and the influence of involvement have been under studied. Results from this study indicate that the students sampled have limited knowledge of e-cig and questions about their safety. However, these factors do not deter users from vaping and others from trying the products. This study sheds light on e-cigs views and use on one university campus and suggests avenues 
for future inquiry as well as factors to consider in future health campaigns (e.g. education on e-cig constituents). 


\section{REFERENCES}

Amrock, S. M., Zakhar, J., Zhou, S., \& Weitzman, M. (2015). Perception of e-cigarette harm and its correlation with use among U.S. adolescents. Nicotine \& Tobacco Research, 17(3), 330-336. https://doi.org/10.1093/ntr/ntu156

Blu. How much do e-cigs cost? E-cig \& vapor cigarette prices. (2017). Retrieved from: http://www.blucigs.com/much-e-cigs-cost/

Bullen, C., Howe, C., Laugesen, M., McRobbie, H., Parag, V., \& Williman, J. (2013). Electronic cigarettes for smoking cessation: A randomized controlled trial. Lancet, 382(9905), 1629-37. doi:10.1016/S0140-6736(13)61842-5

Case, K., Crook, B., Lazard, A., \& Mackert, M. (2016). Formative research to identify perceptions of e-cigarettes in college students: Implications for future health communication campaigns. Journal of American College Health, 64(5), 380-9. doi:10.1080/07448481.2016.1158180

Cobb, N. K., Byron, M. J., Abrams, D. B., \& Shields, P. G. (2010). Novel nicotine delivery systems and public health: The rise of the "e-cigarette." American Journal of Public Health, 100(12), 2340-2342. doi:10.2105/AJPH.2010.199281 
Cooper, M., Loukas, A., Harrell, M., \& Perry, C. (2017). College students' perception of risk and addictiveness of e-cigarettes and cigarettes. Journal of American College Health, 65(2), 103-111. doi:10.1080/07448481.2016.1254638

Corey, C., Wang, B., Johnson, S., Apelberg, B., Husten, C., McAfee, T., King, B., Bunnell, R., Arrazola, R., \& Dube, S. (2013). Notes from the field: Electronic cigarette use among middle and high school students—United States, 2011-2012. Morbidity and Mortality Weekly Report, 62(35), 729-730.

Dawkins, L., \& Corcoran, O. (2013). Acute electronic cigarette use: Nicotine delivery and subjective effects in regular users. Psychopharmacology, 231(2), 401-407. doi:10.1007/s00213-013-3249-8

Drummond, M. B., \& Upson, D. (2014). Electronic cigarettes. Potential harms and benefits. Annals of the American Thoracic Society, 11(2), 236-242. doi:10.1513/AnnalsATS.201311-391FR.

Duke, J. C., Lee, Y. O., Kim, A. E., Watson, K. A., Arnold, K. Y., Nonnemaker, J. M., \& Porter, L. (2014). Exposure to electronic cigarette television advertisements among youth and young adults. Pediatrics, 134(1), e 29-36. doi:10.1542/peds.2014-0269 
Eissenberg, T. (2010). Electronic nicotine delivery devices: Ineffective nicotine delivery and craving suppression after acute administration. Tobacco Control, 19, 87-88. doi:10.1136/tc.2009.033498

Jidong, H., Kornfield, R., Szczypka, G., \& Emery, S. L. (2014). A cross-sectional examination of marketing of electronic cigarettes on Twitter. Tobacco Control, 23(S3), iii26-iii30. doi:10.1136/tobaccocontrol-2014-051551

King, B. A., Alam, S., Promoff, G., Arrazola, R., \& Dube, S. (2013). Awareness and ever use of electronic cigarettes among U.S. adults, 2010-2011. Nicotine \& Tobacco Research, 15(9),1623-1627. doi:10.1093/ntr/ntt013

King, B. A., Patel, R., Nguyen, K. H., \& Dube, S. R. (2015). Trends in awareness and use of electronic cigarettes among U.S. adults, 2010-2013. Nicotine \& Tobacco Research, 17(2), 219-227. doi:10.1093/ntr/ntu191

Kong, G., Morean, M. E., Cavallo, D. A., Camenga, D. R., \& Krishnan-Sarin, S. (2015). Reasons for electronic cigarette experimentation and discontinuation among adolescents and young adults. Nicotine \& Tobacco Research, 17(7), 847-854. https://doi.org/10.1093/ntr/ntu257

Larson, E., \& Pearlman, D. N. (2016). Use of emerging tobacco products among adolescents who do not smoke conventional cigarettes. Rhode Island Medical Journal, 99(6), 45-47. 
Li, J., Bullen, C., Newcombe, R., Walker, N., \& Walton, D. (2013). The use and acceptability of electronic cigarettes among New Zealand smokers. New Zealand Medical Journal, 126, 48-57.

Meyer, M. G., Toborg, M. A., Denham, S. A., \& Mande, M. J. (2008). Cultural perspectives concerning adolescent use of tobacco and alcohol in the Appalachian mountain region. The Journal of Rural Health, 24(1), 67-74. http://doi.org/10.1111/j.1748-0361.2008.00139.x

Palazzolo, D. L. (2013). Electronic cigarettes and vaping: A new challenge in clinical medicine and public health. Frontiers in Public Health, 1, 56. doi:10.3389/fpubh.2013.00056

Polosa, R., Morjaria, J. B., Caponnetto, P., Campagna, D., Russo, C., Alamo, A., et al. (2013). Effectiveness and tolerability of electronic cigarette in real-life: A 24month prospective observational study. Internal Emergency Medicine. 9, 537-546. doi:10.1007/s11739-013-0977-z

Rigotti, N. A. (2012). Strategies to help a smoker who is struggling to quit. Journal of American Medical Association, 308(15), 1573-1580. doi:10.1001/jama.2012.13043 
Saddleson, M. L., Kozlowski, L. T., Giovino, G. A., Goniewicz, M. L., Mahoney, M. C., Homish, G. G., \& Arora, A. (2016). Enjoyment and other reasons for electronic cigarettes use: Results from college students in New York. Addictive Behaviors, 54, 33-39. doi:10.1016/j.addbeh.2015.11.012.

Schraufnagel, D. E., (2015). Electronic cigarettes: Vulnerability of youth. Pediatric Allergy, Immunology, and Pulmonology, 28(1), 2-6. doi:10.1089/ped.2015.0490

Sherwod, C. L., \& Boitano, S. (2016). Airway epithelial cell exposure to distinct ecigarette liquid flavorings reveals toxicity thresholds and activation of CFTR by the chocolate flavoring 2,5-dimethypyrazineara. Respiratory Research, 17, 57. doi:10.1186/s12931-016-0369-9

Smith, L., Brar, K., Srinivasan, K., Enja, M., \& Lippmann, S. (2016). E-cigarettes: How "safe" are they? Journal of Family Practice, 65(6), 380-385.

Sottera, Inc. v. U.S. FDA, Volume 80 Issue 186 (United States District Court District of Columbia, 2010).

Sutfin, E. L., McCoy, T. P., Morrell, H. E. R., Hoeppner, B. B., \& Wolfson, M. (2013). Electronic cigarette use by college students. Drug and Alcohol Dependence, 131(3), 214-221. doi:10.1016/j.drugalcdep.2013.05.001 
Tierney, P. A., Karpinski, C. D., Brown, J. E., Wentai, L., \& Pankow, J. F. (2016).

Flavour chemicals in electronic cigarette fluids. Tobacco Control, 25(e1), e10e15. doi:10.1136/tobaccocontrol-2014-052175

Trumbo, C. W., \& Harper, R. (2013). Use and perception of electronic cigarettes among college students. Journal of American College Health, 61(3), 149-155. doi:10.1080/07448481.2013.776052

U.S. Food and Drug Administration. (2016). Vaporizers, e-cigarettes, and other electronic nicotine delivery systems (ENDS). Retrieved June 14, 2016, from http://www.fda.gov/TobaccoProducts/Labeling/ProductsIngredientsComponents/u cm456610.htm

Vansickel, A. R., \& Eissenberg, T. (2013). Electronic cigarettes: Effective nicotine delivery after acute administration. Nicotine \& Tobacco Research, 15, 267-270. doi:10.1093/ntr/ntr316

Wagoner, K. G., Song, E. Y., Egan, K. L., Sutfin, E. L., Reboussin, B. A., Spangler, J., \& Wolfson, M. (2014). E-cigarette availability and promotion among retail outlets near college campuses in two southeastern states. Nicotine \& Tobacco Research, 16(8), 1150-1155. doi:10.1093/ntr/ntu081 
Westenberger, B. J. (2009). Evaluation of e-cigarettes. St. Louis, MO: Department of Health and Human Services, Food and Drug Administration, Center for Drug Evaluation and Research, Division of Pharmaceutical Analysis. Available from: http://www.fda.gov/downloads/drugs/Scienceresearch/UCM173250.pdf

Wiseman, K., Cornacchione, J., Wagoner, K., Noar, S., Moracco, K., Teal, R., Wolfson, M., \& Sutfin E. L. (2016). Adolescents' and young adults' knowledge and beliefs about constituents in novel tobacco products. Nicotine \& Tobacco Research, 18(7) 1581-7. doi:10.1093/ntr/ntw009.

Yu, V., Rahimy, M., Korrapati, A., Xuan, Y., Zou, A. E., Krishnan, A. R., Tsui, T., Aguilera, J. A., Advani, S., Crotty Alexander, L., Brumund, K., WangRodriguez, J., \& Ongkeko, W. M. (2016). Electronic cigarettes induce DNA strand breaks and cell death independently of nicotine in cell lines. Oral Oncology, 52, 58-65. doi:10.1016/j.oraloncology.2015.10.018 
APPENDIX A

Student E-cig Survey

\section{Exploration of Young Adults' Attitudes, Perceptions and Use of Electronic Cigarettes}

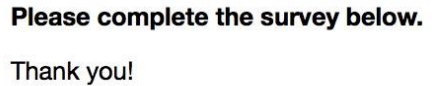

Please complete the survey below.

Thank you!

$\begin{array}{llll}\text { Today's Date } & \\ \text { * must provide value } & \text { Today M-D-Y }\end{array}$

How old are you?

* must provide value

Are you:

What is your academic major?

What year did you start at $U$ of $L$ for your current degree?

In how many credit hours are you currently enrolled?

Roughly, what is your GPA?

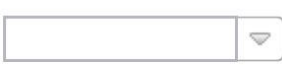

What is your marital status:

Single, never been married

Single, divorced

Married or domestic partner

Separated

Widowed

Please rank how you would describe your current finances on a scale of 1 to 5 , with 5 meaning money is extremely tight and 1 meaning you are not concerned about money what-so-ever? 


\begin{tabular}{|c|c|c|}
\hline & $\begin{array}{l}\text { Good } \\
\text { Fair } \\
\text { Poor }\end{array}$ & reset \\
\hline $\begin{array}{l}\text { I engage in activities that could improve my cardiovascular } \\
\text { health }\end{array}$ & $\begin{array}{l}\text { Everyday } \\
\text { Some days } \\
\text { Rarely } \\
\text { Not at All } \\
\text { Unsure }\end{array}$ & reset \\
\hline I am concerned about my cardiovascular health & $\begin{array}{l}\text { Everyday } \\
\text { Some days } \\
\text { Rarely } \\
\text { Not at All } \\
\text { Unsure }\end{array}$ & reset \\
\hline \multicolumn{3}{|c|}{ In your family, including blood relative of parents, grandparents and siblings, is there a history of the following } \\
\hline \multicolumn{3}{|r|}{ I don't know } \\
\hline \multicolumn{3}{|l|}{ Cancer } \\
\hline \multicolumn{3}{|l|}{ Heart Disease } \\
\hline \multicolumn{3}{|l|}{ Lung or breathing problems } \\
\hline \multicolumn{3}{|l|}{ Obesity } \\
\hline \multicolumn{3}{|l|}{ Other, please specify } \\
\hline \multicolumn{3}{|c|}{ In your family, including non-blood relatives, such as step family, is there a history of the following } \\
\hline Yes & No & I don't know \\
\hline Cancer & & reset \\
\hline \multicolumn{3}{|l|}{ Heart Disease } \\
\hline \multicolumn{3}{|l|}{ Lung or breathing problems } \\
\hline \multicolumn{3}{|l|}{ Obesity } \\
\hline \multicolumn{3}{|l|}{ Other, please specify } \\
\hline $\begin{array}{l}\text { Have you been diagnosed with a heart condition that } \\
\text { requires special medication, diet, or other changes to your } \\
\text { life? }\end{array}$ & $\begin{array}{l}\text { Yes } \\
\text { No } \\
\text { I am not sure }\end{array}$ & reset \\
\hline
\end{tabular}




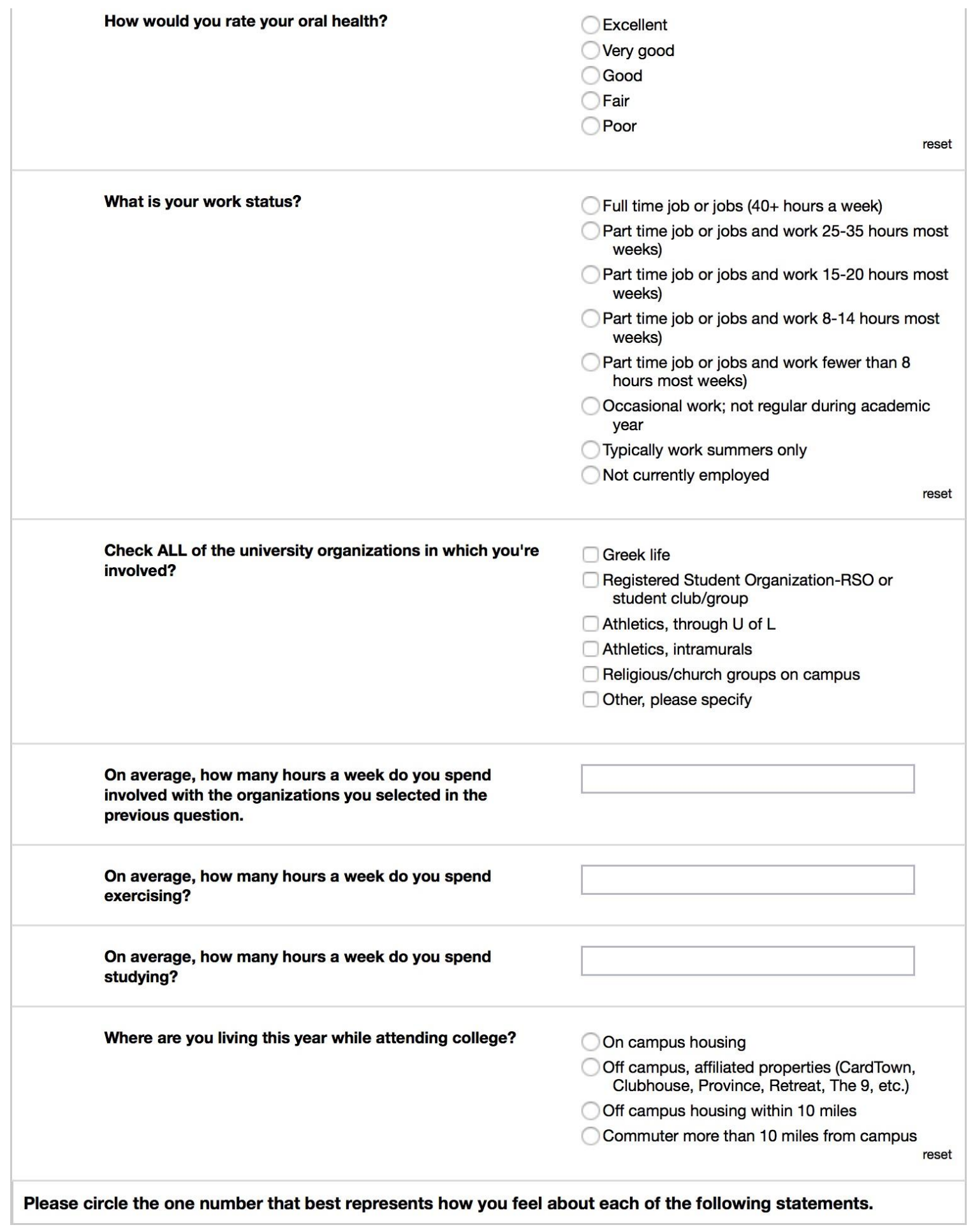




\begin{tabular}{|l|l|l|}
\hline $\begin{array}{l}\text { I (would) like to explore strange } \\
\text { places. }\end{array}$ & $\begin{array}{l}\text { Strongly } \\
\text { Disagree }\end{array}$ \\
\hline $\begin{array}{l}\text { I prefer to be around people who are } \\
\text { excitingly unpredictable. }\end{array}$ & Disagree & Agree \\
\hline I like to do things that scare me. & & restral Agree \\
\hline I like attending wild parties. & reset \\
\hline I would love to try new things, even if \\
they are illegal. \\
\hline I would go skydiving.
\end{tabular}




\section{Exploration of Young Adults' Attitudes, Perceptions and Use of Electronic Cigarettes}

\section{Please complete the survey below. \\ Thank you!}

Had you heard of electronic cigarettes before this survey?

$$
\begin{gathered}
\text { Yes } \\
\text { No }
\end{gathered}
$$

Where have you gotten most of your information about electronic cigarettes?

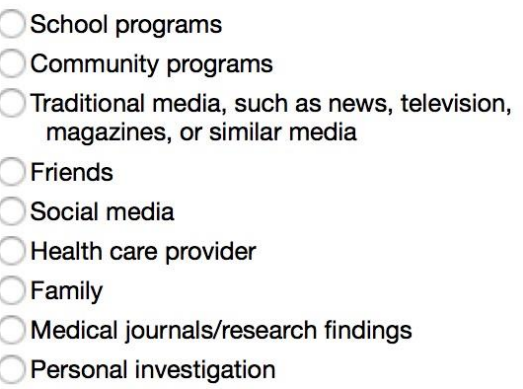

Please finish each of the following sentences with your description.

a. Electronic cigarettes are....

b. Electronic cigarette users are....

If a substance is "generally recognized as safe" (GRAS) by the U.S. Food and Drug Administration (FDA), then it is safe to use by (mark all that apply):
Inhaling (breathing)
Ingesting (eating or drinking)
Applying to skin
Injecting into veins

Please consider each ingredient in the following table. Check the box in the first column if the ingredient is contained in traditional cigarettes, check the box in the second column if the ingredient is contained in electronic cigarettes, and check the box in the third column if the ingredient is harmful. (Check all boxes that apply)

\begin{tabular}{|l|}
\hline Formaldehyde \\
\hline Particulate matter (small particles) \\
\hline Tar \\
\hline Nicotine \\
\hline \\
\hline
\end{tabular}




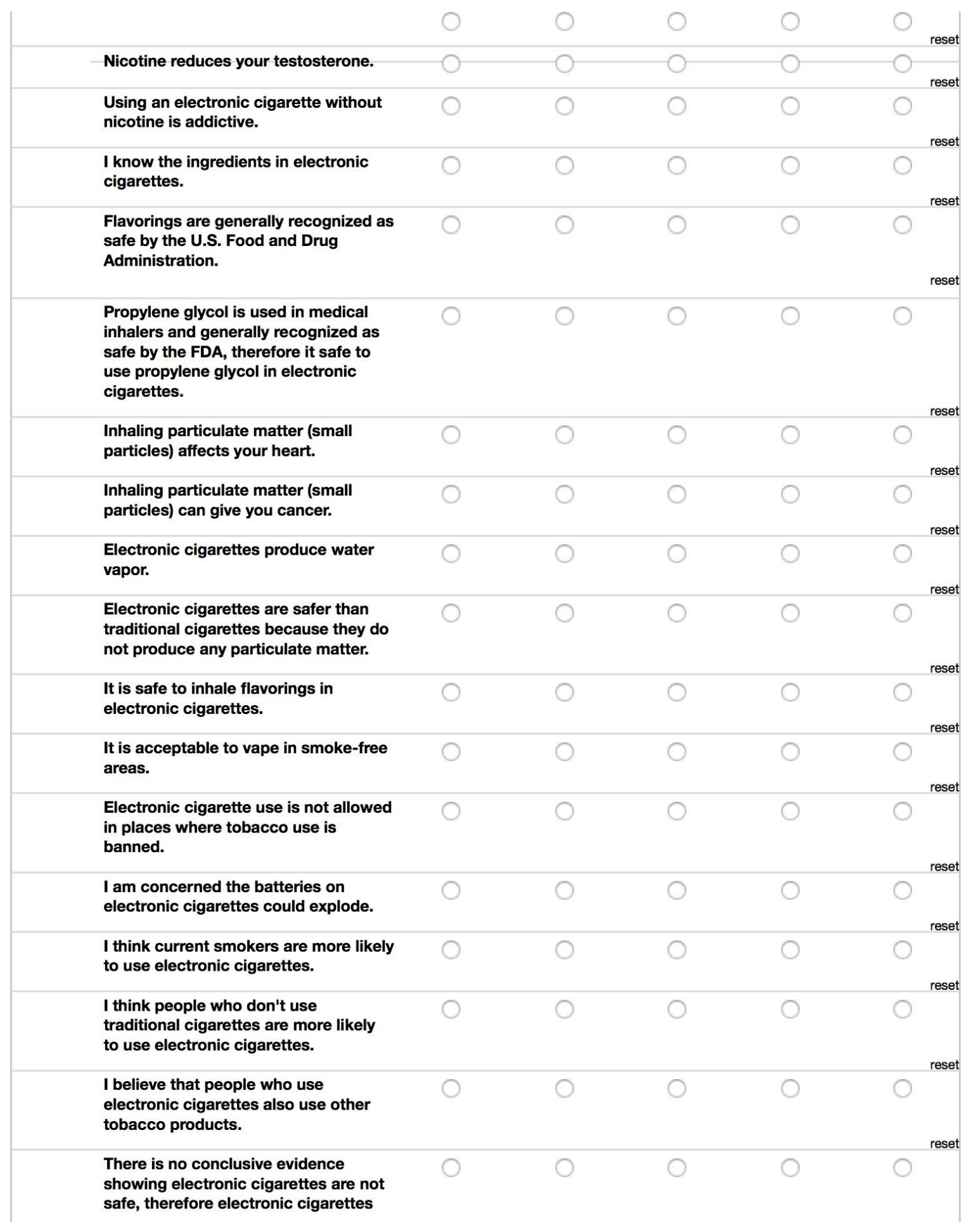


are safer than traditional cigarettes.

People who use electronic cigarettes

in public places are inconsiderate.

Electronic cigarettes are a "fad."

Electronic cigarettes will become more popular than traditional

cigarettes.

Using fruit flavors, like strawberry, in

electronic cigarettes is safer than

using other flavors.

( 10 rese

(1) reset

\begin{tabular}{|l|}
\hline Electronic cigarettes are a "fad." \\
\hline $\begin{array}{l}\text { Electronic cigarettes will become } \\
\text { more popular than traditional } \\
\text { cigarettes. }\end{array}$ \\
\hline $\begin{array}{l}\text { Using fruit flavors, like strawberry, in } \\
\text { electronic cigarettes is safer than } \\
\text { using other flavors. }\end{array}$
\end{tabular}

I am tempted to TRY electronic cigarettes when...

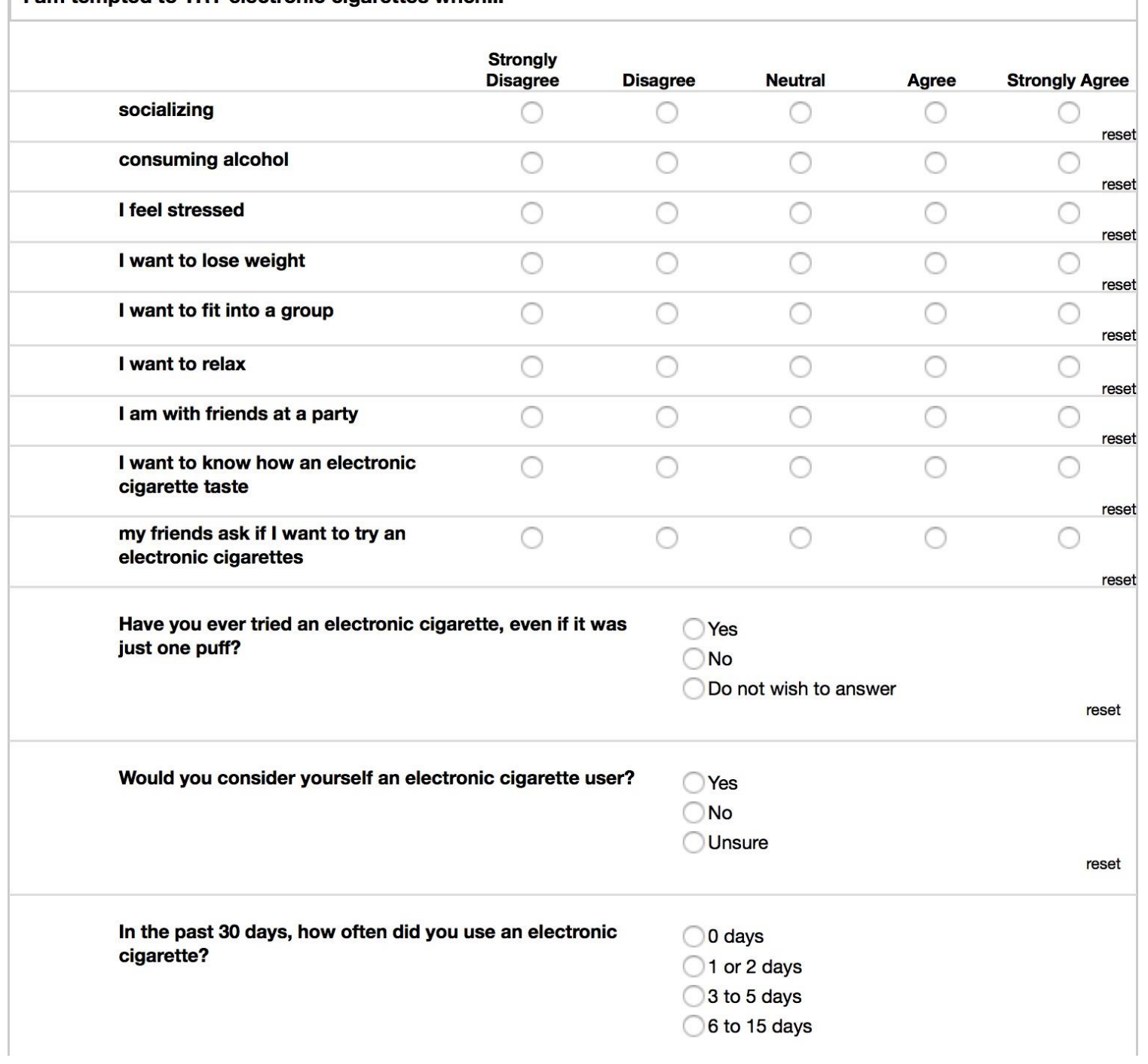




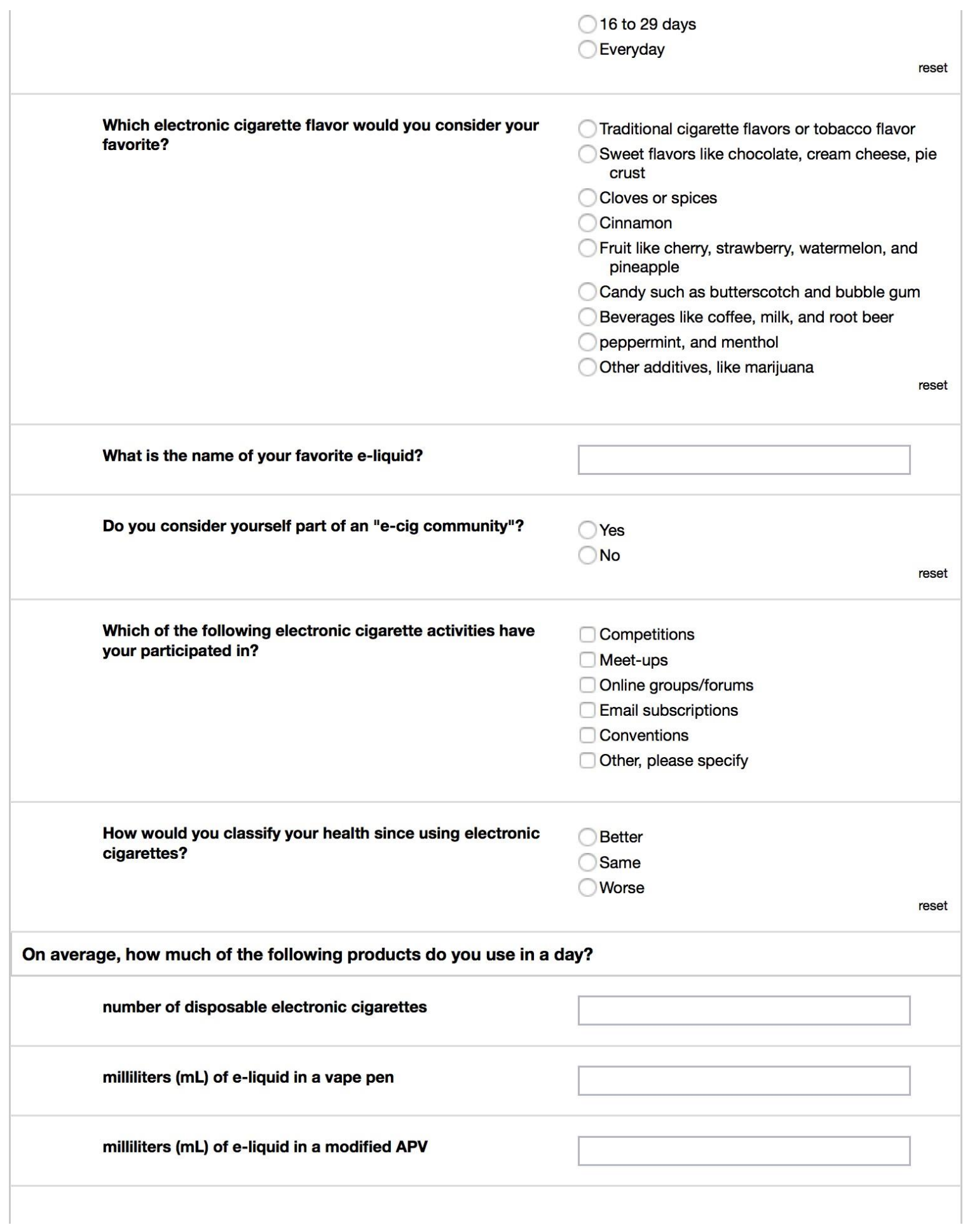




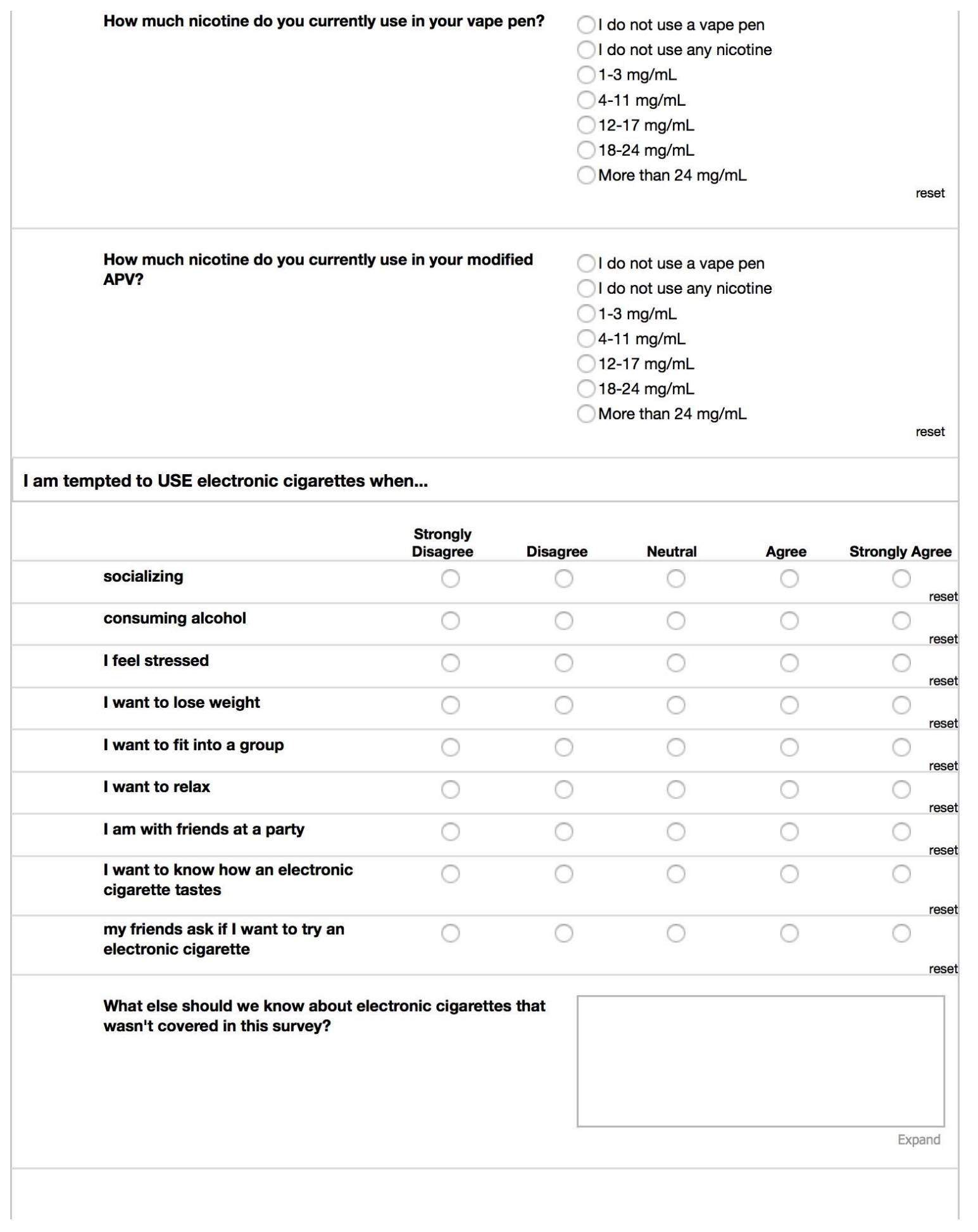

